\title{
Micro-Events in Two Serial Verb Constructions
}

\author{
Chia-Yi Tony Pi \& Osamuyimen T. Stewart \\ McGill University
}

\section{Introduction}

\subsection{Data from Èdó, a Kwa language spoken in Nigeria}

In this paper we propose an aspectual account of two patterns of SVCs (serial verb constructions) in Ėdó, a Kwa language spoken in Nigeria. We intend to extend a theory of aspect developed for non-serial verb languages such as McClure (1994) to true serial verb languages.

Covert Coordinations (CCs) as in (1a,b) are distinct from SVCs as in (2a,b) and $(3 a, b)$. Each verb in a Covert Coordination assigns an independent internal thematic role to its own separate, overt object, among other factors pointed out in Baker (1989) and Collins (1997), among others. There is no object sharing. ${ }^{1}$

a. Òzó gbọó ívìn bòló $\underline{\text { ḱà }}$

Ozo plant coconut peel corn

'Ozo planted coconut and [he] peeled corn.'

b. Òzó lé ízè rrí ôrè

Ozo cook rice eat it

'Ozo cooked rice and [he] ate it.'

a. Òzó kòkó àdésúwà mòsé

Ozo raise Adesuwa be-beautiful

'Ozo raised Adesuwa to be beautiful.'

b. Òzó gbé úkpù guọghhó

Ozo hit cup break

'Ozo hit the cup and it broke.'
a. Òzó lé èvbàré ré
Ozo cook food eat
'Ozo cooked the food and ate it.'
b. Òzó dé èbé tié
Ozo buy book read
'Ozo bought the book and read it.'

In contrast, the two verbs in a SVC assign their internal thematic roles to a single surface object. This internal argument sharing criterion defines the term object sharing. We define SVCs following Stewart (1998) as those constructions in which a single Event head quantifies over the verbs that combine under a single Voice head licensing the subject (Agent). The subject must set about the plan of one event which may be resultative or consequential, i.e., the agent intends a single plan of action that is expressed linguistically by two verbs. 


\subsection{Previous Analyses}

Yet there are at least two views on the internal argument sharing criterion, where a single surface object receives distinct internal thematic roles from two different verbs. Baker (1989) posits a double-headed VP structure wherein the verbs directly theta-mark a single object NP position without an empty category post-V2, for all SVCs. In contrast, Collins (1997) posits that all SVC object sharing is mediated by an empty category, pro, so there would be no true internal object sharing as in Baker (1989).

Stewart (1998) challenges these two views, arguing that there is not a single, unified class as assumed by the aforementioned analyses, but there are in fact two kinds of SVCs with distinct syntactic structures. Resultative SVCs, shown in $(2 a, b)$, have the properties in (4a-d) and the structure in (5).

(4) a. The second verb is always unaccusative. ${ }^{2}$

b. There is a single object NP with no empty category (true object sharing).

c. The two verbs form a co-headed VP (both verbs are non-distinct).

d. Both verbs express a single event that is existentially quantified-over by a single event operator, head of EP (Event Phrase).

(5)

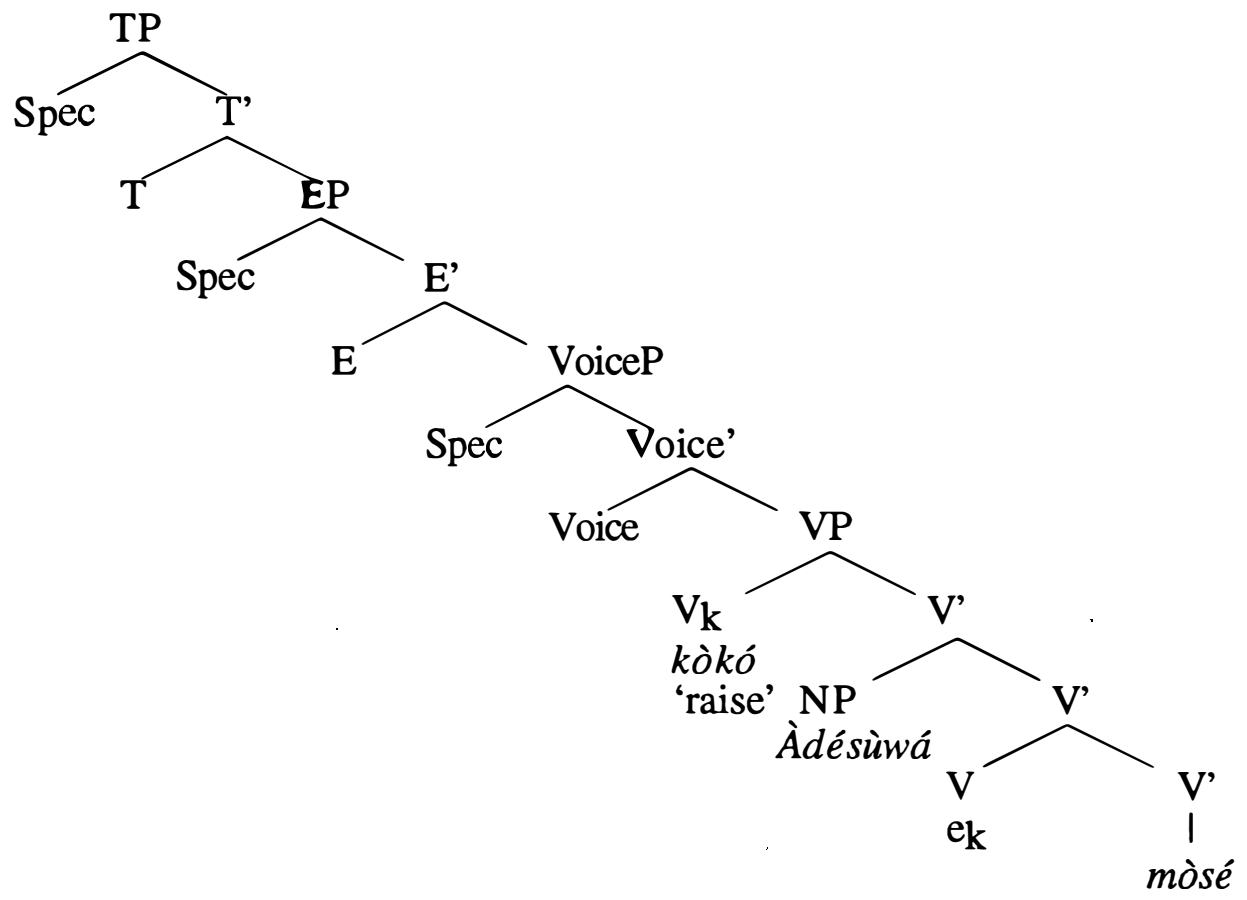

'be beautiful'

Consequential SVCs, shown in (3a,b), have the properties in (6a-e) and the structure in (7):

(6) a. Both verbs must be transitive.

b. Each verb heads a separate VP and expresses an unique event (e1, e2).

c. Each event is licensed by a separate event operator, head of EP.

d. The two (functional) E heads are asymmetric (E1 quantifies over the two events, $\mathrm{e} 1$ and $\mathrm{e} 2$, and binds E2).

e. Object sharing is mediated by an empty category, pro. 


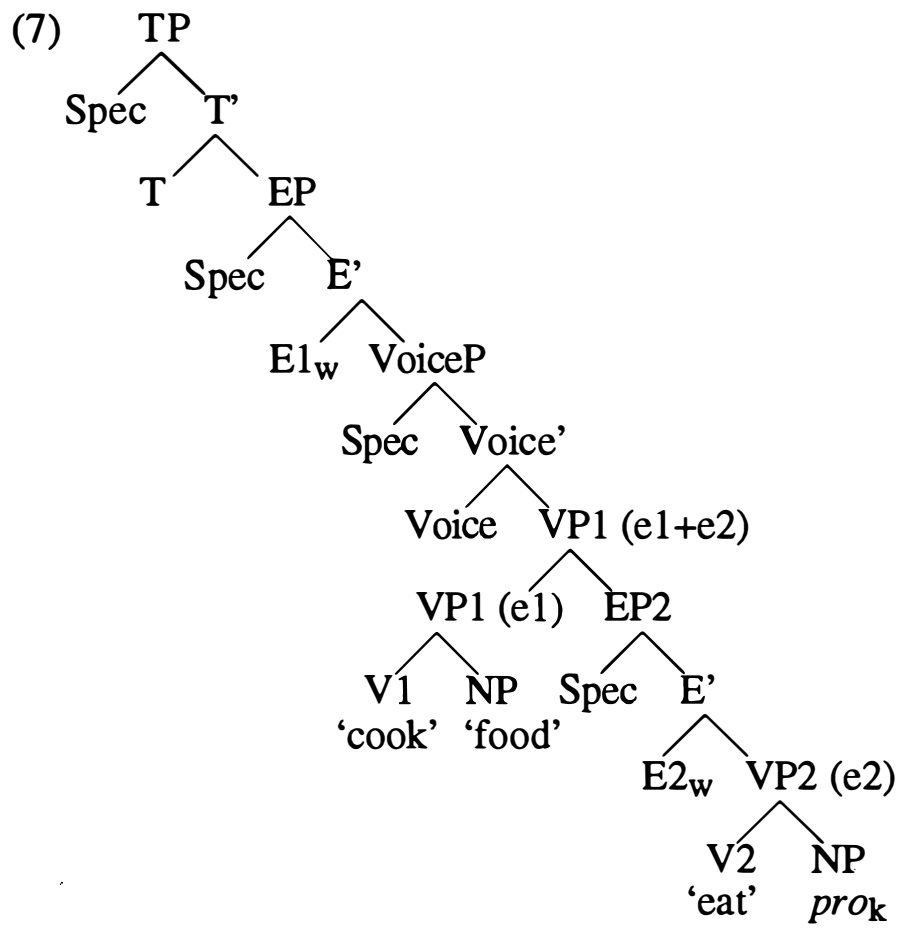

\subsection{Syntactic Tests}

However, previous analyses of SVCs distinguish between resultatives and consequentials by intuition rather than systematically. One exception is Stewart (1998), which claims that a resultative SVC consists of a single event, whereas a consequential SVC consists of multiple events. He uses the following syntactic tests, among others:
a. the anaphoric particle tòbórè
b. INFL-type adverbs, like giégié
c. the iterative morpheme ghá
d. predicate clefts

For the sake of economy, we will only discuss (8a) and (8b). With the test in (8a), the anaphoric adverbial particle tòbórè can only right-adjoin to an NP or an empty category pro that is its antecedent. In a simple sentence with an unaccusative verb as in (9a), the tòbórè particle may appear after the unaccusative verb, taking the trace of the object of an unaccusative verb as its antecedent. In (9b), tòbórè can also be licensed by the object of the verb dùnmwún.

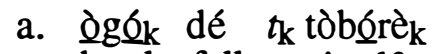
bottle fall itself

'The bottle fell, itself (alone).'

b. Òzó dùnmwún ìyán tòbórè $_{k}$

Ozo pound yam itself

'Ozo pounded the yam, itself.'

We observe in (10a) that it is ungrammatical for the particle to appear after the unaccusative verb, implying that there is no empty category after the second. 
verb in resultative SVCs. In contrast, in the consequential SVC (10b), there is an empty category, pro, after the second verb to which the particle can right-adjoin.

a. *Òzó sùá d̀g $\sigma_{\mathbf{k}}$ dé pro $\mathbf{k}_{\mathrm{k}}$ tòbórè̀ Ozo push bottle fall pro itself

b. Òzó dé ìyán $\mathbf{k}$ dùnmwún pro tòbórè̀ $_{\mathbf{k}}$ Ozo buy yam pound pro itself 'Ozo bought the yam and pounded it (itself).'

For the test in (8b), Stewart assumes that INFL-type adverbs are licensed as left-adjuncts to the head of EP. Since the EP is taken to represent an event in the syntax, the distribution of INFL-type adverbs will match up with the number of EPs to reflect one or two events; that is, either resultative or consequential.

The INFL-type adverb giégié, which means 'quickly', cannot appear before V2, as shown in the resultative SVC in (11a). However, consequential SVCs can have a pre-V2 INFL-type adverb as in (11b). Thus, Stewart predicts that there is a single event in resultative SVCs but two in consequential SVCs.
a. *Òzó sùá Àdésúwà gié!gié dé.
Ozo push Adesuwa quickly fall
'Ozo pushed Adesuwa down quickly.'
b. Òzó dùnmwún èmà gié!gié khiến.
Ozo pound yam quickly sell
'Ozo pounded the yam and quickly sold it.'

\section{Event Mereology and Micro-Events}

\subsection{Event Mereology}

We propose a systematic aspectual account for these two SVCs that operates on the notions of micro-events and macro-events. Since the theory we are developing focusses on event parts and wholes, we call it Event Mereology.

Event Mereology holds at its core several familiar concepts, one of which follows Galton (1985), that change can be perceived in two and only two modes: as a change of state (which is a Transition from a $\neg$ phase to an $s$ phase), and as a state of change (which is a Process phase that leads up to the moment of change).

That Processes and Transitions are used in the calculus of aspect is not unfamiliar (cf. Pustejovsky 1991). These two modes, that of Processes and Transitions, form the basic elements used in our Event Mereology. Event Mereology upholds the principle that the basic unit for an event of change is minimally a Process or a Transition, as in (12a) and (12b), and maximally a combination of both, as in (12c). This minimal event of change is what we call a micro-event $(E)$.

$$
\begin{aligned}
& \text { a. E activities } \\
& \text { P (transitives) } \\
& \text { c. E accomplishments } \\
& \text { II (properties of both transitives/unaccusatives) } \\
& \text { P T most complex micro-event possible }
\end{aligned}
$$


A macro-event $(M)$ is compositionally built from multiple micro-events, as shown in (13a,b). Two Processes or two Transitions can occur as a single macroevent $(13 \mathrm{a}, \mathrm{b})$ but not as a single micro-event $(13 \mathrm{c}, \mathrm{d})$. The prediction that the Transition-Transition combination (as in 13b) cannot be a micro-event is problematic, since the data seems to contradict the prediction. We will discuss possible solutions to that problem later in this paper.

a.

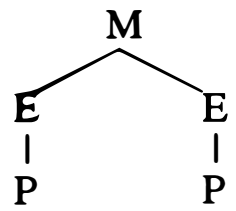

c. b.<smiles>[Y]C(F)CP[3H]</smiles>

d.

\subsection{Aspectual and Syntactic Classes}

To connect micro-events in Event Mereology with the analysis of resultative and consequential SVCs, we take as a starting point several ideas that have their origins in Dowty (1979) and were further developed in McClure (1994), extending the scope of McClure's analysis of accomplishments in non-SVC languages to serial verb languages.

It is observed that accomplishments have no unique aspectual properties that justifies them as a separate aspectual class. Rather, accomplishments are aspectually ambiguous. All accomplishment predicates are syntactically complex, having activity counterparts that are syntactically simpler.

For example, the predicates build and read, typically classified as accomplishments, show an achievement/activity ambiguity. They are activities in $(14 \mathrm{a}, \mathrm{b})$, but in their transitive use build shows the semantics of an achievement (15a), and read shows a semantic ambiguity between achievement and activity (15b). Thus, it is shown that so-called accomplishment verbs can be interpreted as activities, while sometimes permitting achievement interpretations.
a. John built for an hour (but still hadn't built anything).
(activity)
b. John read for an hour.
(activity)

a. John built a house $*$ for an hour/in an hour.

(accomplishment)

b. John read a book for an hour/in an hour.

(activity/accompl)

From these and other observations, McClure argues that accomplishments are activities syntactically, but achievements semantically. We extrapolate from his argument that accomplishments are events with both activity and achievement components.

It has also been observed that not all languages exhibit the same freedom in transitivity alternations as English. However, the verb 'read' in Ėdó behaves like its English counterpart, as seen in the parallelism between (14b), (15b) and (16a), (16b) respectively. Thus, we assume that accomplishments are complex in Ėdó as well.
a. Òzó tiérè là áwá ôkpá
Ozo read for hour one
'Ozo read for an hour.' 
b. Òzó tìe ebé là / vbè áwá ôkpá
Ozo read book for / in hour one
'Ozo read a book for an hour/in an hour.'

Also, McClure argues that there is a semantic motivation for the split between unaccusatives and unergatives, observing that only states and achievements are unaccusative. Conversely, all activities must be unergative.

We adopt his analysis of states and achievements as unaccusative. Since Event Mereology classifies states and achievements as Transitions, we predict Transitions to be unaccusatives canonically.

However, we differ from McClure, who claims that activities are all unergative. Instead, we believe that the Ėdo SVC data shows that the canonical Process is transitive. As for unergatives, we will follow Hale \& Keyser (1993) in analyzing unergatives as underlying transitives with a covert cognate object. (17) summarizes the correspondences between the aspectual and syntactic classes we are proposing.
Activities
Achievements
$\begin{array}{ll}\approx & \text { Transitives } \\ \approx & \text { Unaccusatives }\end{array}$
$\approx \quad$ Processes $(P)$
$\approx \quad$ Transitions $(T)$

McClure's claim that there are two kinds of transitive verbs derived from unergatives and unaccusatives, as illustrated by (18) and (19), is compatible with Hale \& Keyser's cognate object analysis, and we will see how well their proposal supports our analysis of SVCs.
a. John baked.
b. John baked a cake.
bake: unergative
a. The bottle broke.
b. John broke the bottle.
break: unaccusative

We will show that the connections between the semantic and syntactic components shown in (17) work quite well in explaining the 2 different classes observed in Èdo SVCs.

\subsection{Micro-Events and Serial Verb Constructions}

Unique to our Event Mereology analysis is the idea that micro-events are basic. As mentioned earlier, a micro-event may have at most two kinds of parts defined on it, that is, Process or Transition. A simple schematic of how these parts are defined on an event is shown in (20).

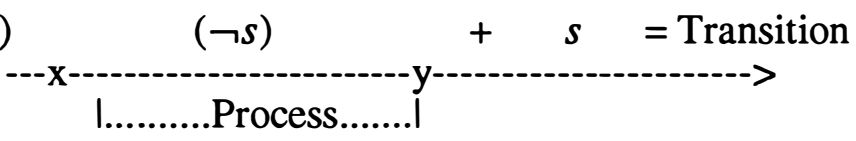

A Process is a single phase that spans the duration of the entire micro-event, shown as the interval from $x$ to $y$. A Transition is an ordered pair of states $\neg$ and $s$. A distinguished point inherent to the event, shown as $y$, bisects the event into two complementary state phases: the lexically specified endstate $s$, and the incipient state, $\neg s$, which is derived from $s$ by complementation.

Event Mereology hypothesizes that language can only grammaticalize a single process or point of change for each morpheme. A verb can either represent the process phase of an event, or the point of transition of that event. However, a 
verb cannot encode more than a single point of transition nor more than a single process. This constraint on minimal specification of change forces verbs that describe change to be as simple as possible lexically.

Of course, there are differences between SVC languages and non-SVC languages. McClure's account of accomplishments covers non-SVC languages like Japanese, English and Italian. We believe that in such non-SVC languages, adjectives and prepositions can compositionally form SVC-like accomplishments.

We argue that adjectives and prepositional particles are analyzed as Transitions in English when used in resultative constructions, which are always accomplishments in English. Any state $s$, such as defined by an adjectival or prepositional proposition, can define a phase on an event. Its complementary phase, $\neg s$, is derived. Two such complementary, adjacent phases give us a Transition, as was shown in (20).

$V+P$ and $V+\operatorname{Adj}(21 \mathrm{a}, \mathrm{b})$ appear to always have a resultative meaning, and are micro-events in English. For example, in (21b) the table was originally not clean, but then as a result of the action becomes clean. That is a clear example of a Transition, going from a state of being \{not clean\} to \{clean\}. However, serial verbs are not permitted in English, as (21c) shows. (See Stewart 1998 for a detailed discussion of the serial verb parameter distinguishing Èdó from English.)
a. John pushed the table over.
$(V+P)$
b. John wiped the table clean.
$(V+A)$
c. *John pushed the table rolled.
$(V+V)$

In SVC languages like Èdó, the availability of a V2 is a crucial factor. Like English, Èd $\delta$ allows $V+A d j$ and $V+P$ combinations. Yet serial verb languages differ from English in one respect: two verbs may compositionally define a single event. Whereas adjectives and prepositions are by default states and can be used to generate a Transition, as previously discussed, the V2 can be lexically specified as either a Process or a Transition, giving us a broader range of verb classes.

So, only a true SVC language like Èdó can build V+V sequences like (21c), be it a macro- or micro-event. Thus the presence of $\mathrm{V} 2$ provides the basis for the observed split between resultative and consequential SVCs from an aspectual perspective, where Process-plus-Transition micro-events contrast with Processplus-Process macro-events.

Since only two modes of perception of change are available to express the change occurring in a single micro-event, we predict at most three possible kinds of micro-events that involve change, which we had shown earlier in (12a-c).

We analyze accomplishments and resultatives as micro-events that exhibit a juxtaposition of the two modes of change, as was given in (12c). These modes, Process and Transition may be expressed simultaneously in a micro-event, but they form the most complex micro-event allowed. We propose that is this highly constrained event structure which yields the differences between resultative and consequential SVCs.

\subsection{Resultative and Consequential Serial Verb Constructions}

In a resultative SVC, the two verbs are causally related. We propose that this causal relation is a characteristic that obtains only in the case where the two verbs can be interpreted as a single micro-event. This causal relationship is shown in $(22 a, b)$. 
a. Òzó sùá Uyi dé

Ozo push Uyi fall

'Ozo pushed Uyi and made him fall.'

b. Òzó gbé èmá!tôn pèrhé

Ozo hammer metal flat

'Ozo hammered the metal flat.'

A resultative SVC (rSVC) exhibits the following characteristics:

(23) a. the V1 of an rSVC must be an activity verb and never a stative, achievement or accomplishment verb,

b. it can only have one event delimiter,

c. just like accomplishment verbs, it can only be modified by in an hour, not for an hour.

These facts are shown respectively in (24):
a. *Òzó bó òwá mòsé
Ozo build house be-beautiful
'Ozo built the house to be beautiful.'

b. *Òzó má úkpù zèzé guòghô

Ozo mould cup hard break

'Ozo moulded the cup so hard that it broke.'

c. Òzó kòkó àdésúwà mòsé vbè ùkpó ìsến/ *là ùkpó ìsén

Ozo raise Adesuwa be-beautiful in year five/*for year five

'Ozo raised Adesuwa to be beautiful in five years/*for five years.'

In contrast, in a consequential SVC, the verbs exhibit temporal ordering rather than causation. We follow Gruber (1992), where it is argued that complex micro events involve a precedence/consequence relation. We propose that the lack of a causal relationship between a consequential SVC's V1 and V2 is predicted by their inability to juxtapose in a single micro-event. V1 and V2 in a consequential SVC must belong to separate micro-events.

There are also no such rigid aspectual constraints as those cited in (23) that require the two verbs in a consequential SVC to be interpreted as a single event instead of two separate events, as the data in (25) show.

a. Òzó bó dwá khiên

Ozo build house sell

'Ozo built the house and sold it.'

b. Òzó miến úkpù dé khiên

Ozo see cup buy sell

'Ozo saw the cup, bought it and sold it.'

c. Òzó dé ékpò ízè lé là ùkpó ìsén/vbè ùkpó ìsến

Ozo buy bag rice eat for year five/in year five

'Ozo bought a bag of rice and ate it for five years/in five years.' 
If the two verbs in a SVC belong to separate micro-events, then the two micro-events in the SVC form a macro-event instead. A consequential SVC can be classified as a macro-event, in which the temporal ordering relation is dominant. Covert Coordinations, which con join multiple Event Phrases, are similar to macroevents. Since their structure and behaviour is too complicated to go into here, we will only discuss the two SVCs in detail. (See Stewart 1998 for a discussion on Covert Coordinations.)

Our proposal accounts for these three observations about resultative SVCs in Èdo, summarized in (26):

a. V1 is always a process and V2 is always an endstate or achievement verb, because of syntactic constraints on the realizations of the two components of the resultative

b. a rSVC only has one event delimiter because a micro-event has just one point of transition

c. it behaves like an accomplishment because the event structure of the resultative SVC is the same as an accomplishment.

Given this data, we stand by our analysis that resultative SVCs have the same internal event structure as accomplishments in non-SVC languages, and that a unified eventive analysis of accomplishments in both types of languages is possible.

\section{Four Possible Patterns}

\subsection{The Four Combinations}

We check our predictions by examining possible V1 and V2 combinations. (27) summarizes what the four possible patterns with Process and Transitions are. Data on the members of these classes are given in the ensuing subsections.

$\underline{\mathrm{V} 1}$

a. Process (transitive)

b. Transition

c. Process

d. Transition
$\underline{\mathrm{V} 2}$

Transition (unacc)

Process

Process

Transition
Predicted $\quad \underline{\text { Data }}$

rSVC rSVC $\mathrm{CC} \quad \mathrm{CC}$

cSVC $\quad$ cSVC cSVC rSVC

\subsection{Process-Transition and Transition-Process}

(27a), that of a Process V1 followed by a Transition V2, is exactly what our theory predicts would yield a single micro-event, as shown in (27a'). Yet we see that in (27b) there is also a Process-Transition combination, except V1 is the Transition and V2 is the Process. Here we have the opposite extreme: two events conjoined by parataxis, with the sole difference being word order.

$$
\begin{array}{ll}
\mathrm{a} . & \mathrm{E} \\
\text { / } \mathrm{I} \\
\mathrm{P} \mathrm{T}
\end{array}
$$


We assume that Process is realized as V1 and the Transition as V2 in a resultative SVC, since following Dowty (1979), the DO operator is structurally higher than the BECOME operator, thereby dictating the order of Process before Transition for a micro-event. Processes cannot be licensed in the lower position, but must be higher structurally, adjacent to the DO operator. Stewart (1998) and Travis (1994) likewise support this structural ordering. We then expect that a micro-event's set of \{Process, Transition\} components must always be linearized with Process in V1 position and Transition in V2.

What of the surface ordering of Transition followed by Process, shown in (27b)? Such an ordering is observed, but this ordering is only permissible as a Covert Coordination, as in (28), where there is a clear intonational break (as indicated by the comma). Covert Coordinations are very free in their structure, since many different kinds of VPs or events may be conjoined.

Òzó dé, lé èvbàré

Ozo fall cook food

'Ozo fell, and (he) cooked food.'

The Transition-Process ordering is not a consequence of the linearization of the two components of a micro-event. Our theory correctly predicts that only the $<\mathrm{P}, \mathrm{T}\rangle$ ordering is observed for a micro-event, and that the instance of a $\langle\mathrm{T}, \mathrm{P}\rangle$ ordering is expected to be a Covert Coordination. (29) has a typical $<\mathrm{P}, \mathrm{T}>$ order but can have a clear intonational break, signalling the presence of a Covert Coordination, thereby distinguishing it from a resultative SVC. We tentatively conjecture that Covert Coordinations are possibly macro-events conjoining two micro-events, as in (27b'), or conjunctions of two macro-events as in (27b"), as shown below, pending further investigation into Covert Coordinations.

Òzó sùá Uyi, dé

Ozo push Uyi fall

'Ozo pushed Uyi, and Ozo fell.'
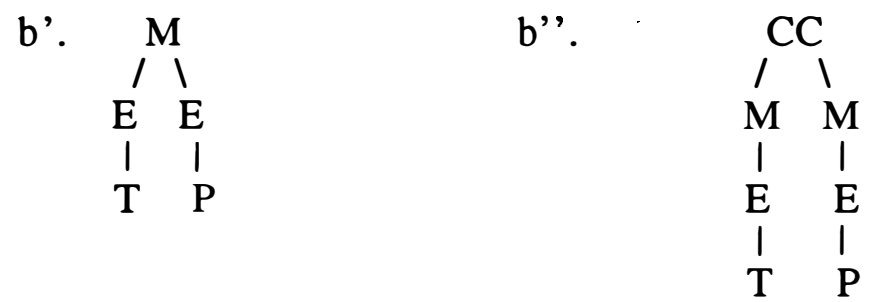

\subsection{Process-Process}

The $<\mathrm{P}, \mathrm{P}>$ ordering in $(27 \mathrm{c})$ is a case where there is object sharing (cf. Déchaine 1993, Baker 1989, Collins 1997, et al.), but it is neither a resultative SVC syntactically nor semantically. As Event Mereology predicts, two Processes cannot form a single micro-event. Instead, they project separate micro-events, and a SVC that contains two micro-events must be a macro-event (27c'). If the surface string of a macro-event shows apparent object sharing, then the SVC is consequential.

$$
\begin{array}{ccc}
c^{\prime} . & \mathrm{M} \\
& / & 1 \\
& \mathrm{E} & \mathrm{E} \\
\mathrm{I} & \mathrm{I} \\
& \mathrm{P} & \mathrm{P}
\end{array}
$$


Note that we are able to stack more verbs in a consequential SVC as in (30a), but not in an resultative SVC (30b). According to our theory, such stacking would be permissible in a consequential SVC, since we are dealing with temporal ordering rather than causation.

$\begin{array}{llllll}\text { a. Òzó dé } & \text { ìyán lé } & \text { ré } & \text { consequential SVC } \\ \text { Ozo } & \text { buy yam cook eat } & \end{array}$ 'Ozo bought the yam, cooked it, and ate it.'

b. *Òzó gbé àkhé ghuòghó kànmwán resultative SVC Ozo hit pot break be.short 'Ozo broke the pot into small pieces.'

Consequential SVCs are more free than resultative SVCs in stacking, because in a macro-event, we do not have the strict requirement of being just a Process plus a Transition. We can stack more than two micro-events together to form a macro-event, as shown in (31). Thus, our aspectual classification also explains why the stacking phenomenon is observed in consequential SVCs but not observed in resultative SVCs. Covert Coordinations are of course rather free in conjoining multiple entities, and likewise permit such stacking.

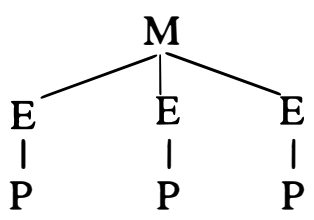

Furthermore, it is observed that consequential SVCs always involve transitive verbs in both V1 and V2 position. The restriction that a consequential SVC consists of a transitive V1 and a transitive V2 is predicted by our theory. Recall that pro is present in the consequential SVC structure, whereas the resultative SVC has true object sharing. If we adopt Hale \& Keyser (1993)'s analysis of unergatives having at D-structure underlying cognate objects, then in a consequential SVC where only the first verb is overtly transitive, the object position of V2 is filled by an empty category that acts as the underlying cognate object. This empty category corresponds to pro in Collins (1997), Baker \& Stewart (1997), and Stewart (1998), allowing tòbórè to right adjoin.

\subsection{Double Unaccusatives}

Lastly, we examine (27d). According to our theory, we predict TransitionTransition SVCs to be macro-events (cf. 13b). However, the data in (32a,b) suggest that these SVCs are micro-event resultative SVCs, since there is a strong causative meaning in these constructions. We will refer to this set of data as the double unaccusative SVCs.

a. ògó dé guòghó

'The bottle fell (and as a result of the falling it) broke.'

b. Òzó dé wú

Ozo fall die

'Ozo fell (and as a result of the falling he) died.' 
Although the data seem to be counterexamples to our aspectual classification, we consider some possible solutions as summarized in (33a-e).

a. certain verbs lexically marked to behave as Processes in V1 position

b. DO makes all unaccusative verbs in V1 Processes

c. SVC languages permit Transition + Transition micro-events

d. a more complex distinction: Transition, Process, Result

e. the V2 is not a Transition but is an emphatic: cf. The river froze solid.

First, we observe that the class of double unaccusative SVCs is rather limited. We find only a few examples of these SVCs, where the V1 is usually dé 'fall' or guòghó 'break'. It could be that these resultative SVCs are exceptions, governed by lexical properties. The verbs that seem to be Transitions (unaccusatives) a re lexically specified to permit a Process reading in V1 position.

Another possible solution we have been contemplating is that the proximity of the DO operator to V1 changes an unaccusative in that position into a transitive Process. However, it would not explain why the class of double unaccusative SVCs is so limited.

A third hypothesis is that it could be a unique property of serial verb languages that permit a micro-event to have two Transitions, because these languages permit two $\mathrm{V}$ heads in a single VP projection. Yet this solution would weaken the strong hypothesis maintained by Event Mereology, that a single event of change has only two modes of perception and grammaticalization, and that is a result we would like to avoid. The fact that this class is extremely limited in productivity compared to true resultative SVCs also suggests that this solution is not correct.

A fourth possibility is that there is a tripartite instead of a bipartite division of micro-events, where we have Transition, Process, and Result. So, in (32a), dé 'fall' is a Transition and guòghó 'break' is the Result of that Transition. This solution would provide for richer variations in the verb classes, but it would require a re-evaluation of the Event Mereology hypotheses.

A related solution is that the V 2 in these apparent $<\mathrm{T}, \mathrm{T}\rangle$ resultative $\mathrm{SVCs}$ is actually emphatic, much in the way of sentences like $(34 a, b)$, pointed out by Levin (1993).

a. The river froze.

b. The river froze solid.

In these sentences, the verb freeze already implies a resultant state of solidity, since the river froze solid is roughly synonymous to the sentence the river froze. The addition of the adjective solid to (34a) does not render the sentence ungrammatical. Note, however, that there is a difference between (34a) and (34b). In (34a), the river does not have to be completely frozen, whereas in (34b), there is a sense of complete solidity. The adjective in (34b) contributes an emphatic sense, extending the implicature of solidity associated with freeze to an entailment of solidity.

In the same vein, perhaps the apparent $<\mathrm{T}$, $\mathrm{T}\rangle$ construction is really a microevent with a single $\mathrm{T}$, and the $\mathrm{V} 2$ is a kind of emphatic modifying the end-result of the V1 transition, instead of being an independent Transition. Possibly, the verb dé 'fall' has an implicature of damage, and the verbs guòghó 'break' and wú 'die' provide entailments of damage much in the same way that freeze and solid are related to one another.

At present we do not find any one solution to be superior to the others. Since double unaccusatives remain a problem for most analyses of SVCs, such as 
the problem of the case-assigning morpheme $y i$ in Ewe discussed in Collins (1997), we are comfortable in leaving double unaccusative SVCs for further investigation.

\section{Conclusion}

In summary, our analysis contributes to the understanding of serial verb constructions by making explicit the internal aspectual structure of events. We hypothesized that accomplishments are micro-events composed of Process-plusTransition phases, and that resultative SVCs are micro-events. By having a distinction between micro-events and macro-events, we are able to account for the differences between resultative and consequential SVCs.

Hopef ully, our analysis will encourage further cross-linguistic comparisons of accomplishment constructions in non-serial verb languages with resultatives and consequentials in serial verb languages from an event structure perspective.

\section{Endnotes}

*We would like to thank Brendan Gillon, Mark Baker, Lisa Travis, and Jonathan Bobaljik for their much appreciated input and support. All errors are of course our own.

1. In the transcription system we have adopted for the Èdo data, lax vowels are indicated with an underscore, e.g., [o]

2Unaccusative verbs in Èdó includes stative verbs, as pointed out in Baker \& Stewart (1997).

\section{References}

Baker, M. (1989) 'Object sharing and projection in serial verb constructions,' Linguistic Inquiry 20, 513-553.

Baker, M. \& O.T. Stewart (1997) 'Unaccusativity and the adjective/verb distinction: Èdó evidence,' NELS 27 Proceedings, 33-47.

Collins, C. (1997) 'Argument sharing in serial verb constructions,' Linguistic Inquiry 28, 461-497.

Déchaine, R-M. (1993) Predicates Across Categories: Towards a CategoryNeutral Syntax. Ph.D. dissertation, U. of Massachussetts, Amherst.

Dowty, D. (1979) Word Meaning and Montague Grammar. Dordrecht: Reidel.

Galton, A. (1984) The Logic of Aspect. Oxford: Oxford University Press.

Gruber, J. (1992) 'Thematic configurational constraints in serial verb constructions,' presented at ACAL, Michigan.

Hale, K. \& J. Keyser, eds. (1993). The View from Building 20: Essays in Linguistics in Honour of Sylvain Bromberger. Cambridge: MIT Press.

Levin, B. (1993) English Verb Classes and Alternations: A Preliminary Investigation. Chicago: University of Chicago Press.

McClure, W. (1994) Syntactic Projections of the Semantics of Aspect. Ph.D. dissertation, Cornell University.

Pustejovsky, J. (1991) 'The syntax of event structure,' Cognition 41, 47-81.

Stewart, O.T. (1998) The serial verb construction parameter. Ph.D. dissertation, McGill University.

Travis, L. (1994) 'Event phrase and a theory of functional categories,' 1994 CLA Proceedings, 559-570. 